\title{
INSERÇÃO DE MULHERES NO MERCADO DE TRABALHO: UM ESTUDO BIBLIOMÉTRICO DA PRODUÇÃO CIENTÍFICA NO PERÍODO DE 2009-2019
}

\author{
Almiralva Ferraz Gomes, Universidade Estadual do Sudoeste da Bahia \\ almiralva@gmail.com \\ Aline Zaíde Pinheiro Matos Santos, Universidade Estadual do Sudoeste da Bahia \\ zaidealine@gmail.com \\ Kelliane de Jesus Nascimento, Universidade Estadual do Sudoeste da Bahia \\ kellianeadmnascimento@gmail.com \\ Beatriz Rodrigues Silva Bockorni, Universidade Estadual do Sudoeste da Bahia \\ beatrizrsbockorni@gmail.com
}

\section{RESUMO}

Gênero é um componente característico das relações sociais e que se imiscui com as relações de poder, sobretudo, no mundo do trabalho. A presença feminina no mercado de trabalho intensificou-se nas últimas décadas, no entanto, as atividades exercidas ainda reproduzem estereótipos de gênero construídos socialmente. A partir de uma pesquisa bibliométrica, o presente artigo tem como objetivo analisar a produção científica, do período de 2009 a 2019, da base Scielo e dos anais de eventos promovidos pela ANPAD (Associação Nacional do Cursos de Pós-graduação em Administração), relacionada a inserção de mulheres no mercado de trabalho, principalmente em espaços predominantemente masculinos. O presente trabalho verificou que na Área de Administração há uma predominância de estudos qualitativos, com autoria majoritariamente feminina. A maior parte dos artigos que debate relações de gênero é de autoria de mulheres doutoras. Ademais, a análise dos artigos revelou que as mulheres ainda dão preferência a carreira pública, principalmente pela estabilidade financeira.

Palavras-chave: Administração, Gênero, Mercado de Trabalho, Mulheres.

Data de recebimento: 09/04/2020

Data do aceite de publicação: 19/11/2020

Data da publicação: 30/12/2020 


\title{
INSERTION OF WOMEN IN THER LABOR MARKET: A BIBLIOMETRIC STUDY OF THE SCIENTIFIC PRODUCTION ABOUT 2009-2019
}

\author{
Almiralva Ferraz Gomes, Universidade Estadual do Sudoeste da Bahia \\ almiralva@gmail.com \\ Aline Zaíde Pinheiro Matos Santos, Universidade Estadual do Sudoeste da Bahia \\ zaidealine@gmail.com \\ Kelliane de Jesus Nascimento, Universidade Estadual do Sudoeste da Bahia \\ kellianeadmnascimento@gmail.com \\ Beatriz Rodrigues Silva Bockorni, Universidade Estadual do Sudoeste da Bahia \\ beatrizrsbockorni@gmail.com
}

\begin{abstract}
Gender is a component of social relations and is intertwined with power relations, especially in the world of work. The female presence in the labor market has intensified in recent decades, however, the activities carried out still reproduce socially constructed gender stereotypes. Based on a bibliometric search, this article aims to analyze the scientific production, from the period 2009 to 2019, of the Scielo database and the proceedings of events promoted by ANPAD (National Association of Postgraduate Courses in Administration), related the insertion of women in the labor market, mainly in predominantly male spaces. The present study found that in the Administration there is a predominance of qualitative studies, with mostly female authorship. Most of the articles that discuss gender relations are authored by women doctors. Furthermore, the analysis of the articles revealed that women still prefer public careers, mainly due to financial stability.
\end{abstract}

Keywords: Administration, Genre, Labor market, Women.

\section{INTRODUÇÃO}

A inserção de mulheres no mercado de trabalho vem crescendo com o passar dos anos, o que gera impactos nas esferas econômicas e sociais, apesar de as pesquisas sobre o tema ainda não se destacarem como foco dos Estudos Organizacionais (GOMES; SANTANA; ARAÚJO, 2009). O predomínio de homens nas esferas produtivas influencia os Estudos Organizacionais e, por conseguinte, a produção científica da área de Administração, que acaba reforçando estereótipos de gênero logo que as empresas são criadas por homens e para eles (CAPPELLE; MELO, 2007). Estudos recentes, no entanto, mostram que cerca de $59,5 \%$ da população ocupada é constituída por mulheres, o que indica sua crescente participação no mercado de trabalho (MUNIZ; BACHA; PINTO, 2015). Desta forma, as discussões a respeito das relações de gênero na sociedade e no mercado de trabalho vêm crescendo, assim como tem se tornado objeto de pesquisa e ganhado espaço relevante nas publicações científicas.

Tendo em vista a crescente participação feminina no mundo do trabalho, sobretudo, em profissões construídas socialmente como masculinas e a existência de uma produção acadêmica que investiga tal fenômeno na contemporaneidade, através de uma pesquisa bibliométrica, o presente trabalho se propõe então a analisar as produções científicas, do período compreendido entre 2009 e 2019, nas base Scielo e nos anais dos eventos promovidos pela ANPAD (Associação Nacional dos Cursos de Pós-graduação 


\section{INSERÇÃO DE MULHERES NO MERCADO DE TRABALHO: UM ESTUDO BIBLIOMÉTRICO DA PRODUÇÃO CIENTÍFICA NO PERÍODO DE 2009-2019}

em Administração), que investigaram assuntos relacionados a inserção das mulheres no mercado de trabalho, principalmente em ambientes considerados masculinos. Após esta introdução, o artigo discute a presença de mulheres e suas relações no mundo do trabalho e, posteriormente, apresenta a metodologia adotada assim como o resultado da pesquisa bibliométrica realizada. Por fim, faz suas considerações finais a respeito do estudo.

\section{AS MULHERES E SUAS RELAÇÕES NO MUNDO DO TRABALHO}

Para compreender como se dá as relações de trabalho e a inserção da mulher no mundo do trabalho, é preciso entender o conceito de gênero. Giddens (2005), ao diferenciar sexo e gênero, define sexo como uma construção física que designa as características genéticas e anatomofisiológicas dos seres humanos, enquanto gênero como um conceito relativo à construção social do sexo que, inclusive, surgiu nos anos de 1970, nas Ciências Sociais. Scott (1995) já define gênero como um elemento constitutivo de relações sociais baseado nas diferenças percebidas entre os sexos e uma primeira forma de significar as relações de poder. Santos e Antunes (2013, p. 44), inclusive, defendem que o conceito de androginia pode ser uma forma de equilibrar as relações de gênero e, por conseguinte, de poder. Tomando como base Dynes et al. (1996) e Mucci (1997), Santos e Antunes (2013) resgatam a origem etimológica da palavra "androginia", do grego andro, homem, e gynaika, mulher, e propõem a mistura de características masculinas e femininas dentro de um único indivíduo.

Ao considerar o gênero como uma construção social, a forma como é representado e o espaço que ocupa pode variar de local e de cultura. Brunstien e Coelho Jr. (2006 apud LOCATELLI et al., 2013) ressaltam que gênero é resultado de uma construção social, ou seja, a maneira como se vê a mulher e o homem é estabelecida de acordo com cada sociedade. Isso explica o fato de o homem ser visto como superior na sociedade brasileira, tendo em vista que o machismo e o patriarcalismo ainda se fazem enraizados em nossos pensamentos e, sobretudo, ações, muito embora o discurso de igualdade de gênero esteja presente na maioria das falas. Vale salientar que, em alguns países, as mulheres possuem ainda menos autonomia em função de questões culturais, inclusive, não têm direito nem mesmo de ir à escola.

As construções sociais, que estabelecem estereótipos de dominação dos homens sobre as mulheres, reforçam, portanto, a submissão sexual e econômica feminina, ou seja, a relação da mulher com o mercado de trabalho sofre com tais construções (ARROYO; FUENTES; JIMÉNEZ, 2016), ao considerarem que o gênero é uma forte variável de crescimento, tendo em vista que os empreendimentos geridos por mulheres apresentam menores expectativas de crescimento. Desse modo, as construções sociais, a partir das diferenças entre os sexos, interferem diretamente nas relações de gênero, principalmente no que diz respeito às relações entre homens e mulheres.

As mulheres são vistas ao longo da história como submissas, frágeis, emotivas, etc. A elas cabem os trabalhos periféricos e relacionados ao ato de cuidar, os afazeres domésticos e familiares. Em contrapartida, os homens são vistos como mais fortes e dominantes e a eles são destinados cargos de comando e chefia (MOTTA, 2000). A base da sociedade moderna, portanto, é patriarcal e a cultura do patriarcado construiu a ideia de que o homem é o dominador e a mulher a dominada, ou seja, o homem é responsável por prover materialmente a família e a mulher por exercer as funções de cuidado (BAHIA; FERRAZ, 2000). Para Castells (1999), o patriarcalismo se caracteriza pela autoridade que é imposta, institucionalmente, no âmbito familiar, sobre a mulher e os filhos. Além disso, para que o patriarcalismo seja exercido é preciso que permeie 


\section{INSERÇÃO DE MULHERES NO MERCADO DE TRABALHO: UM ESTUDO BIBLIOMÉTRICO DA PRODUÇÃO CIENTÍFICA NO PERÍODO DE 2009-2019}

toda a organização da sociedade, do consumo e produção à legislação, cultura e política. Pinto e Melo (2016a; 2016b) destacam a contribuição bourdieuana a esse respeito, ao se discutir que o homem é culturalmente visto como símbolo de virilidade e superioridadepúblico e a mulher como símbolo de fragilidade e inferioridade-privada.

Tais pressupostos reforçam a relação de laços fortes gerados pelas mulheres e laços fracos adquiridos pelos homens (VALE; SERAFIM; TEODÓSIO, 2011). Os laços fortes estariam ligados às mulheres e desenvolvem-se pelo grande cuidado e contato com a família. Tais características podem ser relacionadas ao símbolo de inferiorprivada. Os lações fracos, característicos no universo masculino, têm o símbolo superior-público e são marcados pelo menor contato com a família, trabalho fora de casa e propensão a ascensão, já que se possui menos laços. Desta forma, nas relações de trabalho, as mulheres necessitam desenvolver os laços fracos para progredir nas relações de negócios e, na maioria das vezes, esses laços fracos estão mais presentes nos homens.

Araújo e Lombardi (2013) verificaram que, além de uma pressão maior sofrida pelos homens para trabalhar e assumir responsabilidades pelo sustento da família, tal estereótipo de gênero contribui para que os homens abandonem os estudos para trabalhar e as mulheres deixem de estudar (em menor proporção) por razões relacionadas à maternidade e ao trabalho reprodutivo. No entanto, as mulheres ainda desempenham uma jornada média de afazeres domésticos maiores (mais que o dobro) se comparada ao dos homens. Em função disso, elas acabam trabalhando mais, mesmo que a jornada masculina no trabalho produtivo seja maior.

Essa divisão sexual do trabalho entre homens e mulheres acaba imoputando a elas o trabalho doméstico e a eles o trabalho produtivo e a consequente dispensa do trabalho doméstico (HIRATA; KERGOAT, 2003). No entanto, segundo Bruschini e Lombardi (2003), as mulheres vêm adentrando áreas profissionais que antes eram consideradas de prestígio unicamente masculino, como a área jurídica. Segundo Bonelli (2016), a mudança na composição por sexo dos profissionais do Direito acentuou-se no Brasil, a partir dos anos 1990 e hoje encontra-se em um patamar de participação em torno de $46 \%$ de advogadas inscritas na Ordem dos Advogados do Brasil. É nesse cenário que os encontros entre trabalho e família se sobressaem transpassando o que foi construído separadamente pelas ideologias profissionais e da masculinidade suprema: de um lado, o profissionalismo, a neutralidade da expertise, a dimensão pública, impessoal e objetiva; do outro, os marcadores da diferença, a vida privada, sua restrição ao âmbito da casa, pessoal e subjetivo.

Nas carreiras jurídicas investigadas por Bonelli (2016), os profissionais atuantes no setor privado são os advogados e as advogadas. Em 2012, a OAB-SP possuía 248.712 inscritos ativos em seus quadros e 45,8\% eram mulheres. $\mathrm{O}$ deslocamento da iminência entre profissão e vida familiar ocorre especialmente com a concentração da participação feminina nas carreiras, provocando inclusive conflitos geracionais entre mulheres profissionais. A pesquisa revelou que várias daquelas que desbravaram suas áreas de atuação deram prioridade a deixar na subjetividade a diferença de gênero, mobilizando-se para desempenhar o trabalho tal como os homens, manuseando suas formas de sentir a profissão para se manter no centro de sua identidade (BONELLI, 2016)

Romper a expectativa de que às mulheres cabe atividades mais de caráter privado do que público como foi a constatação do estudo de Bonelli (2016) nos remete a ideia de que muitas mulheres convivem diariamente com a violência simbólica, a qual se propaga ao longo dos anos, por meio de discursos, posicionamentos e atitudes que reforçam os papeis pré-concebidos pela sociedade. De acordo com o PNUD (2014 apud 


\section{INSERÇÃO DE MULHERES NO MERCADO DE TRABALHO: UM ESTUDO BIBLIOMÉTRICO DA PRODUÇÃO CIENTÍFICA NO PERÍODO DE 2009-2019}

PINTO; MELO, 2016a), o indivíduo não percebe tal violência. No mercado de trabalho, é possível sentir a violência simbólica na divisão sexual do trabalho, ao associar os trabalhos de cuidados às mulheres e os trabalhos de força e maiores prestígios aos homens (BOURDIEU, 2007).

Embora Belle (1993) defenda que é culturalmente cada vez menos aceitável que as empresas continuem oferecendo possibilidades de carreiras diferentes aos homens e mulheres, as disputas de poder e gênero dentro das organizações e as promoções ainda acontecem em função, principalmente, de um processo de divisão sexual do trabalho. Em outros termos, às mulheres cabem os cargos relacionados aos cuidados e de menor nível hierárquico enquanto aos homens as atividades de níveis hierárquicos mais elevados.

Segundo Hirata e Kergoat (2003, p. 113), o "valor" que distingue o trabalho masculino do feminino acaba por definir que a produção "vale" mais do que a reprodução e a produção feminina vale menos do que a produção masculina, mesmo que sejam idênticas. Isso, por sua vez, leva a uma hierarquia social. Assim, mesmo que estejam iguais em direitos, elas permanecem desiguais de fato, visto que não há igualdade nem em remuneração, nem nos empregos ocupados (LAUFER, 2003). Silveira $(2003$, p. 157) salienta que "[...] se as mulheres não recebem o mesmo salário, em primeiro lugar é porque não ocupam os mesmos empregos". Briscuhini e Lombardi (2003, p. 350), inclusive, afirmam que, mesmo que as mulheres ocupem espaços de trabalho com as mesmas características dos ocupados por homens, elas ainda permanecem "submetidas a uma desigualdade de gênero presente em todos os escalões de mercado de trabalho no que tange aos rendimentos: ganham menos do que os colegas de profissão do sexo masculino". Em outros termos, quanto a inserção das mulheres no ambiente de trabalho, a divisão sexual dificulta a sua ascensão profissional, pois ainda sofrem com o fenômeno do "teto de vidro" que, sutilmente, impede seus avanços profissionais. O chamado "teto de vidro" é um fenômeno estudado por muitos pesquisadores e que se trata de um processo sutil de impedimento de avanços profissionais em função do gênero (STEIL, 1997). Ademais, as mulheres ocupam cargos semelhantes, que exigem as mesmas qualificações por salários menores, menos segurança no trabalho e chances menores de chegar a posições em níveis hierárquicos mais altos (CASTELLS, 1999).

No entanto, as mulheres não padecem apenas com as implicações do "teto de vido". Moreira, Fleck e Viana (2019), ao pesquisarem discriminação de gênero, concluíram que a distinção de gênero não acontece explicitamente no ambiente de trabalho, visto que não se manifesta claramente nos hábitos e comportamentos dos indivíduos. A discriminação acontece através do que os autores chamam de "véu", uma cortina de ações que promovem uma conduta discriminatória. Este achado converge com outros estudos que apontam que os trabalhadores afirmam que não existe discriminação no ambiente laboral, no entanto, atitudes implícitas denunciam pensamentos discriminatórios. Tais crenças estão tão enraizados nos sujeitos que eles são incapazes, na maioria das vezes, de perceber.

$\mathrm{O}$ fato de homens e mulheres terem personalidades ou identidades múltiplas e não uma identidade única contribui para a complexidade nas organizações, ou seja, as identidades se cruzam para criar uma identidade mesclada. As maneiras pelas quais as personalidades interagem ou tornam-se destacáveis são importantes para um contexto organizacional. Assim, o estudo de uma identidade envolve, necessariamente, a atenção com sua interação com outras individualidades. Entretanto, quando as categoriais de identidade sócio históricas são comparadas com categorias menos marcadas socialmente, como função organizacional, o significado do sexismo e outras formas de 


\section{INSERÇÃO DE MULHERES NO MERCADO DE TRABALHO: UM ESTUDO BIBLIOMÉTRICO DA PRODUÇÃO CIENTÍFICA NO PERÍODO DE 2009-2019}

dominação nas organizações e na sociedade mais ampla, por exemplo, é negligenciado. Portanto, o estudo das diversas identidades nas organizações deve ser adequado e situado em seu contexto social (NKOMO; COX JR., 2006). Com isso, Nkomo e Cox Jr. (2006) relatam a importância das pesquisas sobre diversidade nos estudos organizacionais, pois elas podem ser capazes de revelar o impacto da identidade sobre os membros de grupos minoritários, conjuntamente, e os efeitos para os membros de grupos majoritários. As pesquisas que revelam que ser mulher têm um efeito negativo nas promoções ou na remuneração também revelam que ser homem tem efeito positivo. $\mathrm{Ou}$ seja, mesmo as pesquisas com enfoque em gênero acabam revelando impactos específicos da diversidade nos resultados das operações das organizações.

Por conta disso, segundo Calás e Smircich (2006), as abordagens do pensamento feminista se conectam com as teorias e práticas organizacionais, desde o acesso da mulher e o seu desempenho nas organizações até a noção de práticas organizacionais influenciadas por relações de gênero. Para elas, cada linha de pensamento oferece alternativas para uma perspectiva da desigualdade de gênero, enquadrando $o$ "problema" de forma diferenciada e propondo diferentes caminhos de ação e solução.

Apesar das dificuldades enfrentadas pelas mulheres, ao longo dos anos, elas veem se empoderando e ocupando seus espaços de direito na sociedade. Os movimentos feministas das décadas de 1960 e 1970 foram essenciais não só para tais avanços quanto para a formulação de teorias feministas que vieram mais tarde subsidiar os estudos organizacionais na forma de estudo emergente, uma vez que o tema ainda está às margens dos estudos organizacionais e ainda é marcado pelo racionalismo e pela ciência normal (GOMES; TEIXEIRA; PIAU, 2016),

Os movimentos feministas, portanto, inspiraram o desenvolvimento de teorias que se manifestaram em três momentos, segundo Gomes, Teixeira e Piau (2016). A primeira fase, a clássica, nasceu como movimento em prol da igualdade de direitos civis, políticos e educativos e da luta contra a desigualdade de direitos. A segunda fase se caracteriza pela busca da igualdade entre homens e mulheres por meio de conquistas sociais e legais. E a terceira fase envolve a discussão das relações entre homens e mulheres, sendo de grande influência para os estudos de gêneros contemporâneos. Narvaz e Koller (2006) destacam ainda que as três fases não devem ser vistas de forma linear, pois sempre existiram e ainda coexistem.

Tomando como base a premissa de que há uma crescente inserção das mulheres no mercado de trabalho, inclusive, em postos considerados predominantemente masculinos, Locatelli et al. (2013), em estudo realizado na Polícia Civil, um ambiente dito como masculinizado, verificaram que, por questões de gênero, muitas mulheres são vistas como um estorvo para o andamento do trabalho masculino em campo. Ao entrevistarem os homens, a maioria revelou a necessidade de proteger suas colegas, muito embora não houvesse diferença no processo de treinamento funcional da carreira de policial. Tal resistência masculina de se trabalhar em campo com mulheres leva a designação da maioria das mulheres à área administrativa, mesmo que elas tenham um desempenho tão bom quanto ao dos seus colegas do sexo masculino.

Na pesquisa de Bonelli (2016), foram investigados magistrados(as) estaduais e federais, promotores(as) e procuradores(as) estaduais e federais, defensores(as) públicos(as) e procuradores(as) do Estado de São Paulo. Havia, em 2011, 2.064 juízes de primeira instância no TJ-SP, sendo 35,7\% de juízas. Na segunda instância, estavam empossados 354 desembargadores, sendo 3,7\% de mulheres, marcando a carreira como predominantemente masculina em seu conjunto, com $68 \%$ de magistrados. A Defensoria Pública do Estado de São Paulo e a Procuradoria Geral do Estado de São Paulo não se organizam em duas instâncias como nas instituições anteriores. As 


\section{INSERÇÃO DE MULHERES NO MERCADO DE TRABALHO: UM ESTUDO BIBLIOMÉTRICO DA PRODUÇÃO CIENTÍFICA NO PERÍODO DE 2009-2019}

mulheres constituíam a maioria, sendo 52\% de defensoras públicas e 55,6\% de procuradoras do estado. Segundo a autora, a Defensoria Pública do Estado de São Paulo mostrou-se mais aberta à diferença e com um maior equilíbrio nas oportunidades de progressão para defensores e defensoras, mostrando o porquê de as mulheres investirem mais em uma carreira no setor público ao invés do setor privado.

Segundo Nishimura, Alperstedt e Feuerrshütte (2012), a participação das mulheres vem se destacando também no empreendedorismo social, impulsionada talvez pela cultura ocidental, que promoveu uma educação feminina focada por muito tempo em atividades relacionadas ao cuidado do lar e da família. No que tange ao mercado de trabalho, esse processo de empoderamento tem refletido de forma significativa o empreendedorismo. Segundo Jonathan (2011), tomando como base o Global Entrepreneurship Monitor (GEM), em 2009, pela primeira vez, o número de mulheres empreendedoras brasileiras (53\%) superou numericamente $o$ de homens empreendedores $(47 \%)$, tanto no empreendedorismo por oportunidade quanto no empreendedorismo por necessidade. No tocante à participação da mulher em atividades empresariais, o Brasil mantém sua posição de destaque: $4^{\circ}$ lugar entre os 37 países que participaram da última pesquisa do GEM (2018). O crescimento da proporção de mulheres no total da população empreendedora saltou de $29 \%$ em 2000 e 2001, para $42 \%$, em 2002, e chegou a $46 \%$, em 2003. No ano de 2016, o número de novas empreendedoras chegou a 51\% (GEM, 2017).

Os achados de Anderson e Woodcock (1996 apud JONATHAN 2011,) a respeito dos principais motivos que levam empreendedoras a empreender (sobrevivência, insatisfação com a liderança masculina, descoberta de um nicho de mercado, satisfação em fazer as próprias decisões) tentam explicar porque muitas mulheres optam pela criação do próprio negócio. Além disso, as mulheres veem no empreendedorismo uma possibilidade de flexibilização, ao ver uma oportunidade de conciliar os afazeres domésticos, os cuidados com os filhos e o trabalho. Em outros temos, elas se sujeitam a condições de sobrecarga de trabalho, pois continuam exercendo a função de trabalhadora, mãe, esposa, etc. No entanto, conforme salienta Machado (1999), ao tornar-se empreendedora, a mulher adquire um espaço de poder, o qual ela transforma de maneira compartilhada, em contraposição à tendência predominante de isolar e estratificar o poder.

Segundo Cappelle e Melo (2007), a crescente inserção do contingente feminino nas organizações tem sido marcada por algumas especificidades que têm alterado os modos de comportamento da mão de obra, bem como da organização do trabalho. Percebe-se também que o nível de escolaridade das mulheres tem sido mais elevado, se comparado ao dos homens que ocupam as mesmas posições que elas (IBGE, 2013). Dessa forma, pode-se também notar um crescente aumento da participação da mulher no meio científico, compondo quase a metade dos pesquisadores com bolsa do $\mathrm{CNPq}-$ Conselho Nacional de Desenvolvimento Científico e Tecnológico (CAPPELLE; MELO, 2007). Esses achados reforçam a importância de se entender este processo dinâmico e recente que é a inserção e as implicações do ingresso da mulher no mercado de trabalho. Deste modo, a próxima seção irá apresentar a metodologia adotada para elaboração da pesquisa.

\section{METODOLOGIA}

A metodologia adotada foi a pesquisa bibliométrica, tendo em vista que tem sido muito utilizada nas ciências sociais aplicadas ao auxiliar na identificação de tendências e compreender melhor o estado da arte de diversos temas em estudo desde "quem já 


\section{INSERÇÃO DE MULHERES NO MERCADO DE TRABALHO: UM ESTUDO BIBLIOMÉTRICO DA PRODUÇÃO CIENTÍFICA NO PERÍODO DE 2009-2019}

fez", "o que fez" e "com quem fez" (QUEVEDO-SILVA et al., 2016). Para a coleta, foi realizado um levantamento de artigos científicos na base ANPAD (Associação Nacional do Cursos de Pós-graduação em Administração) e Scielo, com um recorte temporal de 2009 a 2019. A escolha das bases se justifica pela importância da atuação da ANPAD na produção científica nacional em nível de pós-graduação em Administração. Já a base Scielo foi escolhida, pela sua elevada credibilidade e pelo extenso número de artigos disponibilizados gratuitamente para consulta.

A pesquisa foi realizada em duas etapas. Na primeira etapa, o primeiro critério de seleção no processador de busca foi por palavras chave, tais como: relações de gênero, gênero, polícia, policial, patrulheiro(a), construção social, socialização e feminino(a). Na segunda etapa, esses artigos foram agrupados em uma planilha Excel e organizados por categorias desde o ano de publicação, plataforma publicada, tipo de pesquisa, região, tema, local de publicação, gênero de autoria e titulação dos autores. A próxima seção, portanto, irá apresentar o resultado da pesquisa, ou seja, o estado da arte da produção científica nacional, na base Scielo e nos anais da ANPAD, no período compreendido entre 2009 e 2019, que investigou, sobretudo, a presença de mulheres em segmentos dominados pelos homens.

\section{A PRODUÇÃO CIENTÍFICA NACIONAL: DE 2009 A 2019}

As discussões a respeito das relações de gênero na sociedade e no mercado de trabalho se faz presente nos debates atuais, bem como é objeto de estudo de muitas pesquisas. Ao se pesquisar a base Scielo e os anais da ANPAD, no período de 2009 a 2019, identificaram-se um total de 89 artigos, ou seja, 58 nos anais da ANPAD e 31 na base Scielo. Quanto ao tratamento utilizado nos artigos estudados, pôde-se observar uma predominância de estudos qualitativos (73), o que correspondeu a quase $82 \%$ dos artigos estudados. Apenas nove artigos receberam tratamento quantitativo, isto é, pouco mais de $10 \%$ do total. Sete artigos receberam tratamento quali-quantitativo (aproximadamente 8\% do total). De acordo com Denzin e Lincoln (2005), o uso de abordagens qualitativas na Administração vem crescendo, visto que há temas relacionados à subjetividade no trabalho e comportamento organizacional que são melhor compreendidos através de tratamento qualitativo. Rocha e Ceretta (1998) afirmam que a pesquisa qualitativa, inclusive, pode ser considerada como a mola propulsora do profundo conhecimento sociológico das organizações, por isso, pode contribuir bastante para os estudos organizacionais. A predominância de estudos qualitativos pode ser explicada porque as pesquisas qualitativas estão ocupando um lugar reconhecido entre as várias possibilidades de se estudar os fenômenos que envolvem os seres humanos e suas intrincadas relações sociais que são estabelecidas em diversos ambientes (GODOY, 1995). Ademais, elas possibilitam uma compreensão ampla a respeito das relações de gênero na sociedade.

Quanto a natureza dos artigos, houve uma predominância de estudos empíricos (67). Deste total, 54 eram estudos qualitativos, oito eram quantitativos e cinco qualiquantitativos. De natureza teórica, levantou-se um total de 21 artigos, sendo 19 qualitativos e dois quali-quantitativo. Registou-se apenas um artigo de caráter teóricoempírico e sua abordagem era quantitativa, como é possível verificar no Gráfico 1. 


\section{INSERÇÃO DE MULHERES NO MERCADO DE TRABALHO: UM ESTUDO BIBLIOMÉTRICO DA PRODUÇÃO CIENTÍFICA NO PERÍODO DE 2009-2019}

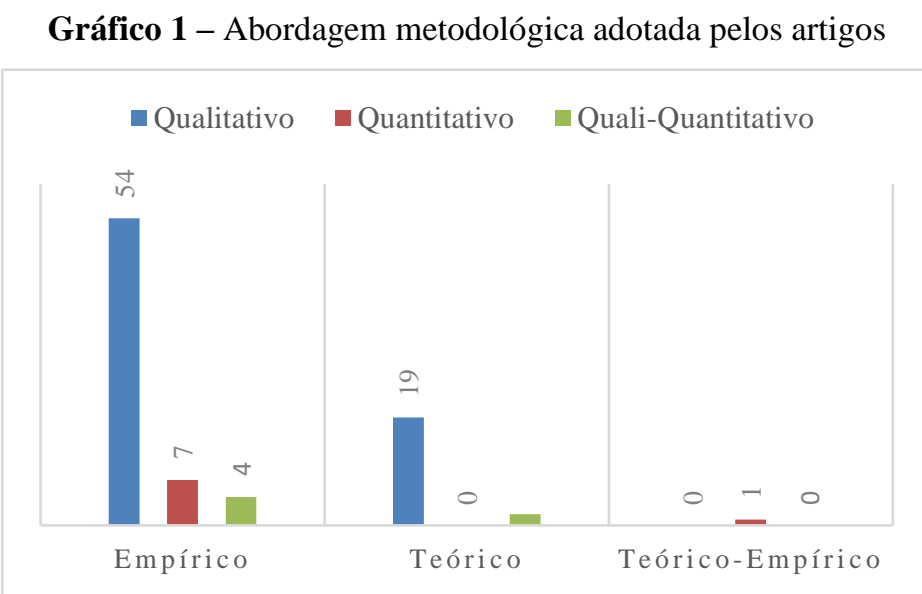

Fonte: Elaborado pelas autoras (2020)

Esses números mostram que as publicações que tratam de relações de gênero levantadas nas bases Scielo e ANPAD, no período investigado, adotaram predominantemente uma abordagem qualitativa e verticalizada do objeto de estudo de modo a buscar mais profundidade no estudo do fenômeno, ao entender como ocorrem as diferenças e como a vida das pessoas envolvidas é impactada.

Ao se analisar os artigos por região, pôde-se observar uma predominância de produção na região Sudeste (51), especificamente Minas Gerais, ou seja, mais da metade das publicações no período estudado foi da região mais rica do país. Em segundo lugar, a região Sul empatado com o Nordeste, ambos com 16 publicações. Levantaram-se três artigos realizados na Europa (um na Espanha, um em Portugal e o outro na França), dois no Centro-oeste e apenas um no Norte do país (Gráfico 2).

Gráfico 2 - Regiões de origem das publicações

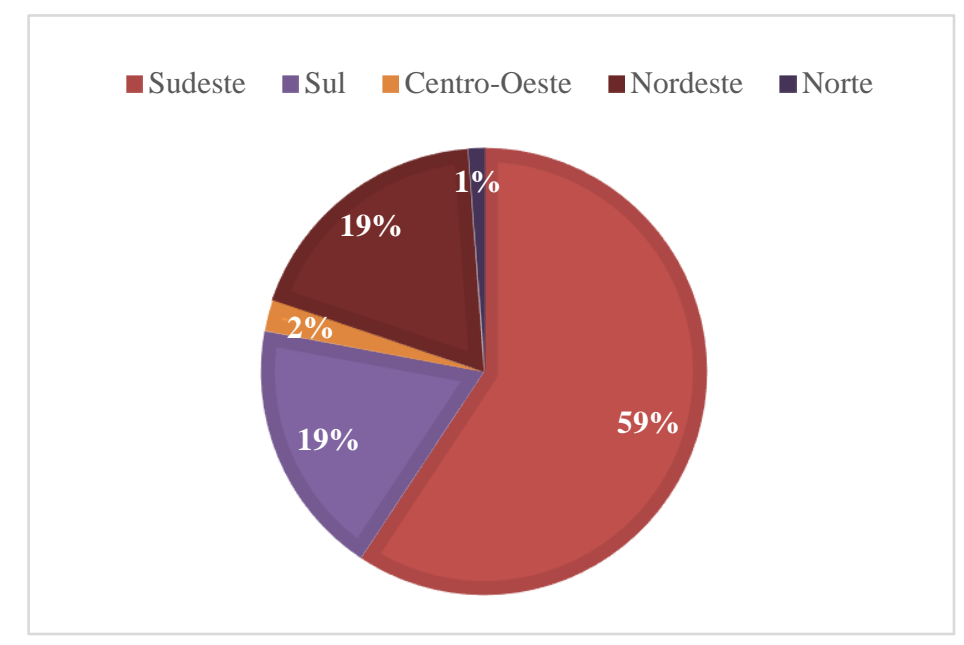

Fonte: Elaborado pelas autoras (2020)

Gomes, Santana e Araújo (2009), ao apresentarem algumas tendências da produção acadêmica nacional e internacional sobre empreendedorismo feminino, com base em uma revisão de literatura, durante o período de 1999-2008, constataram, na produção nacional, apenas 13 artigos publicados na área de empreendedorismo feminino e relações de gênero, enquanto em plataformas internacionais, foi possível levantar 69 artigos relacionados a área. O Gráfico 3 mostra a quantidade de artigos publicados por pesquisadores nacionais, de 2009 a 2019, nas bases estudadas. 


\section{INSERÇÃO DE MULHERES NO MERCADO DE TRABALHO: UM ESTUDO BIBLIOMÉTRICO DA PRODUÇÃO CIENTÍFICA NO PERÍODO DE 2009-2019}

Gráfico 3 - Número de publicações por ano

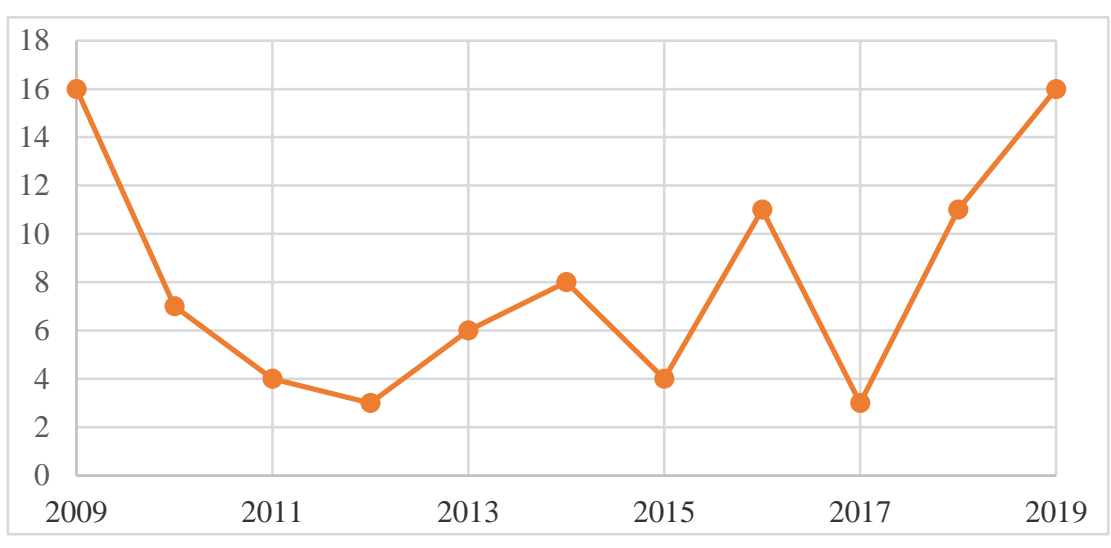

Fonte: Elaborado pelas autoras (2020)

De acordo com o Gráfico 3, os anos de maior número de publicações foi 2009 e 2019 com 16 publicações. Em seguida, 2016 e 2018, ambos com 11 publicações ao ano. Ressalta-se que o total de artigos foi baseado nos eventos da ANPAD e nas publicações da base Scielo.

Dos 89 artigos coletados, destaca-se com maior número de publicações os anais do Encontro da Associação Nacional dos Programas de Pós-Graduação em Administração (EnANPAD) com 38 artigos e, logo em seguida, o Encontro de Gestão de Pessoas e Relações de Trabalho (EnGPR) com nove artigos, conforme é possível observar no Gráfico 4. Vale salientar que tais eventos são promovidos pela ANPAD.

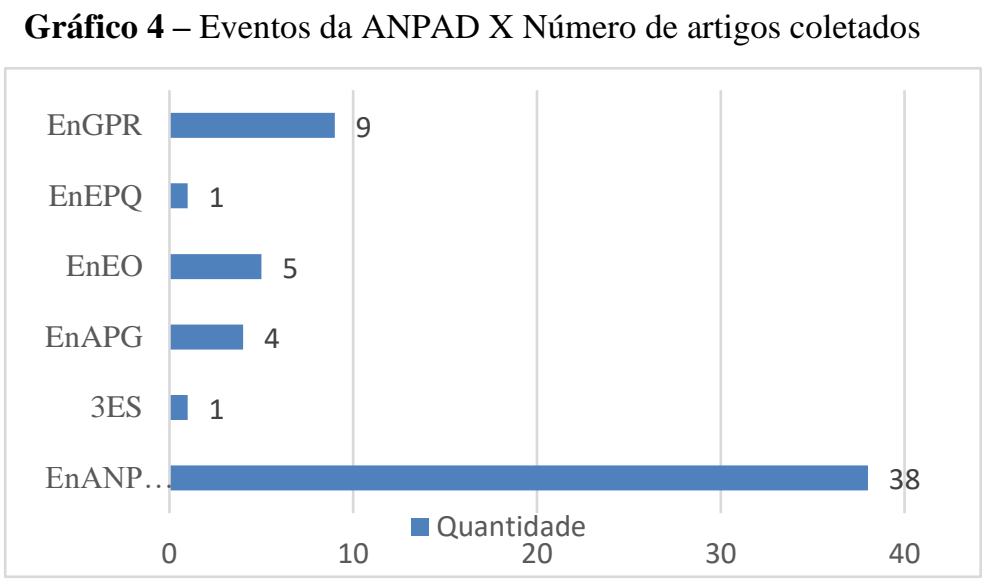

Fonte: Elaborado pelas autoras (2020)

Verificou-se uma predominância de autoria feminina nos artigos publicados. Dos 89 artigos estudados, 51 foram escritos apenas por mulheres, 33 de autoria feminina e masculina e apenas cinco exclusivamente redigidos por homens. Os artigos levantados foram organizados em cinco temáticas: Administração Pública (8); Empreendedorismo (10); Estudos Organizacionais (4); Liderança (4); Relações de Gênero (46); Sustentabilidade (1). Vale ressaltar que mesmo os artigos que têm como foco a Administração Pública, por exemplo, ainda sim abordam assuntos relacionados a relações de gênero e vice-versa.

As mulheres sobressaem-se na escrita de quase todas as temáticas, exceto na temática que trata dos Estudos Organizacionais, pois a maioria foi elaborada por homens e mulheres em conjunto, como pode ser observado na Tabela 2. Dentre as publicações que tratavam da inserção de mulheres em ambientes construídos 


\section{INSERÇÃO DE MULHERES NO MERCADO DE TRABALHO: UM ESTUDO BIBLIOMÉTRICO DA PRODUÇÃO CIENTÍFICA NO PERÍODO DE 2009-2019}

socialmente como masculinos, como o da polícia civil, militar e rodoviária, predominou a autoria de mulheres, com baixa participação masculina na condução desses estudos e com maior número de publicações sobre esse assunto na região Sudeste.

Tabela 1 - Autoria X Tema

\begin{tabular}{ccccc}
\hline Área Temática & \multicolumn{3}{c}{ Autoria } \\
\cline { 2 - 5 } & Feminina & Masculina & Feminino e Masculino & Total \\
Administração Pública & 9 & 2 & 7 & $\mathbf{1 8}$ \\
Empreendedorismo Feminino & 9 & 0 & 6 & $\mathbf{1 5}$ \\
Estudos Organizacionais & 3 & 1 & 6 & $\mathbf{1 0}$ \\
Liderança & 2 & 0 & 2 & $\mathbf{4}$ \\
Relações de Gênero & 28 & 2 & 11 & $\mathbf{4 1}$ \\
Sustentabilidade & 0 & 0 & 1 & $\mathbf{1}$ \\
Total & $\mathbf{5 1}$ & $\mathbf{5}$ & $\mathbf{3 3}$ & $\mathbf{8 9}$ \\
\hline
\end{tabular}

Fonte: Elaborado pelas autoras (2020)

As diferenças nas relações de gênero podem ser observadas de diversas formas. Na pesquisa de Senkevics e Carvalho (2016), realizada com crianças do terceiro ano do ensino fundamental, foi possível observar que as meninas apresentavam melhores desempenhos na escola, assim como envolvimento com as atividades domésticas. Em contrapartida, a maioria dos meninos não tinha o hábito de desenvolver tais atividades, o que reforça o pressuposto de que os serviços domésticos são atividades destinadas às mulheres e construídas socialmente como feminina. Além disso, os autores observaram que ao se questionar as crianças sobre o que queriam ser quando crescer, as meninas tiveram maior clareza sobre o seu futuro, inclusive almejando profissões que demandavam maior escolarização.

A busca pela elevação do grau de escolaridade pretendido pelas meninas pode também ser identificada nos estudos de Tosta (2017), em pesquisa realizada na Universidade Federal de Goiás. A pesquisadora observou que as mulheres superam os homens tanto em número de matrículas quanto em conclusão de cursos da graduação, porém, entre os jovens que não estudam nem trabalham $(23,4 \%)$, há uma maioria de mulheres (68\%), devido ao fato de estarem relacionadas com a maternidade e a dificuldade em conciliá-la com o estudo e a participação em atividade remunerada (IBGE, 2013).

Quanto à titulação dos autores, dos 89 artigos, 67 autores possuíam doutorado e mais da metade deles (41) era de autoria exclusivamente feminina, como pode ser observado na Tabela 2.

Tabela 2 - Titulação X Gênero

\begin{tabular}{lcccc}
\hline & Mulheres & Homens & $\begin{array}{c}\text { Mulheres e } \\
\text { Homens }\end{array}$ & Total \\
\hline Mestrado & 4 & 3 & 2 & $\mathbf{9}$ \\
Doutorado & 41 & 2 & 24 & $\mathbf{6 7}$ \\
Pós-Doutorado & 6 & 0 & 7 & $\mathbf{1 3}$ \\
Total de artigos & $\mathbf{5 1}$ & $\mathbf{5}$ & $\mathbf{3 3}$ & $\mathbf{8 9}$ \\
\hline
\end{tabular}

Fonte: Elaborado pelas autoras (2020).

Esses dados estão de acordo com os levantados realizados por Tosta (2017), que demonstram que as mulheres almejam um maior grau de escolarização se comparado 


\section{INSERÇÃO DE MULHERES NO MERCADO DE TRABALHO: UM ESTUDO BIBLIOMÉTRICO DA PRODUÇÃO CIENTÍFICA NO PERÍODO DE 2009-2019}

aos homens. Assim, a educação torna-se uma fonte de empoderamento e conquista de direitos e ocupação de um lugar no mercado de trabalho.

Quanto às relações de gênero, destaca-se o fato de a mulher ser vista pela sociedade, por séculos, como um ser inferior ao homem. Apesar das mudanças, ainda é possível experimentar resquícios de uma sociedade machista e patriarcal. Pinto e Melo (2016) partem da visão bourdieuana de que o homem é culturalmente visto como símbolo de virilidade e superioridade-público e a mulher como símbolo de fragilidade e inferioridade-privada, para explicar as barreiras enfrentadas pelas mulheres. Por isso, são associadas aos trabalhos domésticos e que envolvem cuidados, enquanto os homens à força e atividade de prestígio.

O empreendedorismo foi destacado como uma forma de empoderamento da mulher, que busca ocupar seu espaço no mercado de trabalho. De acordo com Machado (2012) e Teixeira e Bonfim (2016), a sociedade vê com bons olhos quem empreende, mas ainda vê como algo tipicamente masculino, principalmente se o ramo escolhido for associado a profissões consideradas masculinas. Em outras palavras, a expectativa societal de que determinados segmentos empresariais são mais inclinados para perfis femininos e outros para masculinos reforça a divisão sexual de trabalho que separa o que são atividades para mulheres e o que são para homens.

Gomes, Santana e Araújo (2009), inclusive, salientaram que uma das razões para que mulheres decidam empreender é a flexibilização dos horários, o que lhes possibilita cuidar do trabalho e da família. No entanto, Strobino e Teixeira (2014) afirmam que são raras as mulheres que têm as fronteiras trabalho-família definidas e não sofrem conflitos. As mulheres, mesmo que tenham apoio de terceiros, ainda são responsáveis pelas atividades do lar. Ou seja, mais uma vez a sobrecarga de trabalho nos ombros femininos é motivo de preocupação, conforme foram levantados por Silva (2009) e Carloto (1998).

Em se tratando dos estudos voltados para a Administração Pública, destacou-se o processo de inserção da mulher neste setor e as barreiras enfrentadas. Tendo em vista que o setor público é visado por grande parte da população como forma de estabilidade no mundo laboral e de tratamento igualitário nos processos seletivos, para as mulheres, a carreira no setor público proporciona uma chance de se ingressar no mercado de trabalho e de se ascender profissionalmente. Vaz (2013), inclusive, afirma que as mulheres escolhem cada vez mais o setor público por acreditarem que nele há menos barreiras, uma vez que seu processo seletivo não considera as diferenças de gênero, mas apenas as habilidades por meio dos concursos públicos, além da estabilidade que o setor oferece. Porém, ainda é possível sentir o "teto de vidro" neste setor, uma vez que a ascensão na carreira não leva em consideração apenas critérios objetivos como no processo de contratação.

Boa parte dos autores pesquisados destaca as dificuldades enfrentadas no mercado de trabalho por mulheres, como a dificuldade de se ascender a cargos diretivos. Os desafios são agravados quando as mulheres ocupam a mesma jornada de trabalho dos homens e continuam sendo as responsáveis pelos afazeres domésticos. Ou seja, duplicam sua jornada de trabalho (MACEDO, 2009), o que as sobrecarrega em demasia. Silva (2009) até defende a necessidade de um novo arranjo organizacional que possibilite a inserção da mulher no mercado de trabalho e Carloto (1998) aponta os problemas de saúde causados por essa dupla jornada de trabalho.

É possível notar ainda a violência simbólica dentro das organizações, principalmente no que diz respeito a cargos considerados masculinos, como o de policial. A violência simbólica se propaga ao longo dos anos, por meio de discursos, posicionamentos e atitudes que reforçam os papeis pré-concebidos pela sociedade 


\section{INSERÇÃO DE MULHERES NO MERCADO DE TRABALHO: UM ESTUDO \\ BIBLIOMÉTRICO DA PRODUÇÃO CIENTÍFICA NO PERÍODO DE 2009-2019}

(MELO; PINTO, 2015). Dessa forma, apesar de as mulheres ocuparem cerca de $48 \%$ dos cargos no setor público, em se tratando de cargos de alto nível hierárquico, este número sofre uma queda bastante significativa (ERNST AND YOUNG, 2014). Isso reforça a ideia de empoderamento, iniciado, principalmente, com lutas feministas e que garantiram às mulheres grande parte dos direitos que possuem hoje. Em outros termos, o empoderamento se apresenta como um caminho para que mulheres ocupem de fato um espaço no cenário atual.

\section{CONSIDERAÇÕES FINAIS}

O estudo realizado caracteriza-se como uma pesquisa bibliométrica, na qual se levantou 89 artigos nas bases ANPAD e Scielo. As publicações foram classificadas quanto ao ano de publicação, plataforma, tipo de pesquisa, região, tema, local de publicação e gênero de autoria. $O$ intuito dessa classificação foi o de traçar um perfil das publicações levantadas em tais bases nos últimos anos e analisar o que se tem produzido a respeito da participação de mulheres no mercado de trabalho, principalmente em carreiras consideradas masculinas. A análise dos resultados mostra que a maior parte das publicações se deu na base ANPAD (58), inclusive, a maioria (38) encontrada nos anais do Encontro da Associação Nacional dos Programas de Pós-Graduação em Administração (EnANPAD). Do total de artigos analisados, a maior parte é de estudos empíricos (67), qualitativos (54), produzidos na região Sudeste (51), escritos predominantemente por mulheres (51), com maior titulação de doutorado (41) e o tema mais frequente foi relações de gênero (46).

Os autores dos artigos destacam, em sua maioria, as dificuldades enfrentadas no mercado de trabalho por mulheres, tais como: dificuldade de ascensão a cargos diretivos e dupla jornada de trabalho. Quanto ao empreendedorismo, apesar de ser destacado como forma de empoderamento ainda é visto como algo masculino, principalmente se a área de atuação escolhida for associada a uma profissão construída socialmente como masculina.

Apesar do crescimento da participação de mulheres no mercado de trabalho, ainda se verificam tratamento diferenciado e empecilhos para a sua inserção e crescimento no mercado, de uma forma geral, principalmente em áreas consideradas masculinizadas. No entanto, as lutas feministas e a ideia de empoderamento têm garantido direitos e espaço no mercado de trabalho às mulheres.

O estudo é limitado quanto ao período de investigação e às bases de pesquisa, visto que se buscaram somente artigos entre 2009 e 2019 na base Scielo e nos anais da ANPAD. Recomenda-se, portanto, ampliar o recorte temporal e a base de dados. Fica a recomendação de se estender o estudo a bases não só brasileiras, mas também internacionais.

\section{REFERÊNCIAS}

ARAÚJO, Ângela; LOMBARDI, Maria Rosa. Trabalho informal, gênero e raça no Brasil do início do século XXI. Cadernos de Pesquisa, São Paulo, v. 43, n. 149, p. 452-477, 2013. Disponível em <http://www.scielo.br/pdf/cp/v43n149/05.pdf>. Acesso em 08 out. 2019.

ARROYO, Matilde Ruiz; FUENTES, María del Mar Fuentes; JIMÉNEZ, Jenny María Ruiz. Um estudo internacional sobre os fatores que explicam a expectativa de alto crescimento em novos empreendimentos: uma perspectiva de gênero. Revista 


\section{INSERÇÃO DE MULHERES NO MERCADO DE TRABALHO: UM ESTUDO \\ BIBLIOMÉTRICO DA PRODUÇÃO CIENTÍFICA NO PERÍODO DE 2009-2019}

Brasileira de Gestão de Negócios, São Paulo, v. 18, n. 60, p. 171-190, abr./jun., 2016. Disponível em: <http://www.scielo.br/pdf/rbgn/v18n60/1806-4892-rbgn-18-6000171.pdf>. Acesso em: 01 nov. 2017

BAHIA, Maria Cândida dos Anjos; FERRAZ, Maria Aparecida Viviane. Entre a exceção e a regra: a construção do feminino na polícia civil Baiana. Revista Organizações \& Sociedade, Salvador, v. 7, n. 18, p. 25-40, mai./ago., 2000. Disponível em: $\quad<$ http://www.scielo.br/scielo.php?script=sci_arttext\&pid=s198492302000000200002>. Acesso em: 24 ago. 2019

BELLE, Françoise. Executivas: quais as diferenças na diferença. In: CHANLAT, Jean François (Coord.). O Indivíduo na Organização: dimensões esquecidas.. São Paulo: Atlas, 1993. V. 2.

BONELLI, Maria Gloria. Carreiras jurídicas e vida privada: intersecções entre trabalho e família. Cadernos Pagu, São Paulo, n. 46, p. 245-277, jan./abr., 2016. Disponível em: $<\quad$ http://www.scielo.br/scielo.php?pid=S010483332016000100245\&script=sci_abstract\& tlng=pt >. Acesso em: 01 nov. 2017.

BOURDIEU, Pierre. A dominação masculina. Rio de Janeiro: Bertrand Brasil, 2007. $158 \mathrm{p}$.

BRUSCHINI, Cristina; LOMBARDI, Maria Rosa. Mulheres e homens no mercado de trabalho brasileiro: um retrato dos anos 1990. In: MARUANI, Margaret; HIRATA, Helena (Orgs.) As novas fronteiras da desigualdade: Homens e mulheres no mercado de trabalho. São Paulo: Editora Senac, 2003.

CALÁS, Marta B.; SMIRCICH, Linda. Do Ponto de Vista da Mulher: Abordagens Feministas em Estudos Organizacionais. In: CLEGG, Stewart R.; HARDY, Cynthia; NORD, Walter R. (Orgs.). Handbook de Estudos Organizacionais. São Paulo: Atlas, 2006. p. 274-327.

CAPPELLE, Mônica Carvalho Alves; MELO, Marlene Catarina de Oliveira Lopes. O Cotidiano de Trabalho de Policiais Femininas: Relações de Poder e de Gênero no Policiamento Operacional da Polícia Militar de Minas Gerais. In: ENCONTRO DA ASSOCIAÇÃO NACIONAL DOS PROGRAMAS DE PÓS-GRADUAÇÃO EM ADMINISTRAÇÃO, 31., 2007, Rio de Janeiro. Anais... Rio de Janeiro: ANPAD, 2007. p.1-16.

CASTELLS, Manuel. O poder da identidade. São Paulo: Paz e Terra, 1999.

DENZIN, Norman; LINCOLN, Yvonna. Handbook of qualitative research. 3 ed. Thousand Oaks: Sage publications, 2005.

ERNST AND YOUNG. World wide Women Public Sector Leaders Index 2014: opening the door for women working in government. 2014. Disponível em: <http://www.ey.com/Publication/vwLUAssets/EYWorldwide_Women_Public_Sector_ Leaders_Index_2014/\$FILE/EY_Worldwide_Index_ofWomen_22Oct14.pdf>. Acesso em: 10 out. 2019.

GLOBAL ENTREPRENEURSHIP MONITOR. Empreendedorismo no Brasil: 2016. Curitiba: IBQP, 2017. 
Relatório Global de Empreendedorismo no Brasil. Paraná: IBQP, 2018.

GIDDENS, Anthony. Sociologia. 4a ed. Porto Alegre: Artmed, 2005.

GODOY, Arilda S. Introdução à pesquisa qualitativa e suas possibilidades. RAE, São Paulo, v. 35, n. 2, p. 57-63. Mar./abr. 1995.

GOMES, Almiralva Ferraz; SANTANA, Weslei Gusmão Piau; ARAUJO, Uajará Pessoa. Empreendedorismo Feminino: o estado-da-arte. In: ENCONTRO DA ASSOCIAÇÃO DOS PROGRAMAS DE PÓS-GRADUAÇÃO EM ADMINISTRAÇÃO, 33., 2009, São Paulo. Anais... São Paulo: ANPAD, 2009.

GOMES, Almiralva Ferraz; TEIXEIRA, Simone Andrade; PIAU, Deise Danielle. Teorias Feministas nas organizações: diálogos e intersecções. In: SANTOS, Elinaldo Leal (Org.). Teorias Administrativas Contemporâneas: diálogos e convivência. Vitória da Conquista: Edições UESB; São Paulo: Hucitec Editora, 2016. p. 149-164

HIRATA, Helena; KERGOAT, Danièle. A divisão sexual do trabalho revisitada. In: MARUANI, Margaret; HIRATA, Helena (Orgs.) As novas fronteiras da desigualdade: Homens e mulheres no mercado de trabalho. São Paulo: Editora Senac, 2003.

INSTITUTO BRASILEIRO DE GEOGRAFIA E ESTATÍSTICA. Pesquisa nacional por amostra de domicílios: síntese de indicadores 2012. Rio de Janeiro: IBGE, 2013.

JONATHAN, Eva G. Mulheres empreendedoras: $O$ desafio da escolha do empreendedorismo e o exercício do poder. Psicologia Clínica, Rio de Janeiro, v. 23, n.1, p. 65-85, 2011. Disponível em: <http://www.scielo.br/pdf/pc/v23n1/a05v23n1.pdf\&gt>. Acesso em: 01 nov. 2017.

LAUFER, Jaqueline. Entre a esfera pública e a esfera privada: os desafios dos direitos das mulheres. In: MARUANI, Margaret; HIRATA, Helena (Orgs.) As novas fronteiras da desigualdade: Homens e mulheres no mercado de trabalho. São Paulo: Editora Senac, 2003.

LOCATELLI, Patrícia Augusta Pospichil Chaves et al. Mulheres na Polícia Civil: um olhar sobre as relações de gênero e identidade. Gestão Contemporânea, Porto Alegre, ano 10, n. 14, p. 9-34, jul./dez. 2013. Disponível em: <https://www.lume.ufrgs.br/bitstream/ handle/10183/96847/000915787.pdf?sequence=1\&gt>. Acesso em: 06 nov. 2017.

MACHADO, Francis Berenger. Dilemas de Mulheres Empreendedoras em Empresas Inovadoras Nascentes. In: ENCONTRO DA ASSOCIAÇÃO NACIONAL DOS PROGRAMAS DE PÓS GRADUAÇÃO EM ADMINISTRAÇÃO, 36., 2012, Rio de Janeiro. Anais... Rio de Janeiro: ANPAD, 2012.

MACHADO, Hilka V. Tendências do comportamento gerencial da mulher empreendedora. In: ENCONTRO NACIONAL DA ASSOCIAÇÃO DOS PROGRAMAS DE PÓS-GRADUAÇÃO EM ADMINISTRAÇÃO, 23., 1999, Maringá. Anais... Maringá: ANPAD, 1999. 1 CD-ROM.

MELO, Marlene Catarina de Oliveira Lopes; PINTO, Rosilaine Aparecida. Empoderamento de mulheres na Gestão da Justiça e da Polícia Civil em Minas Gerais. 
In: ENCONTRO DA ASSOCIAÇÃO NACIONAL DOS PROGRAMAS DE PÓS GRADUAÇÃO EM ADMINISTRAÇÃO, 39., 2015, Belo Horizonte. Anais... Belo Horizonte: ANPAD, 2015.

MOREIRA, Martiele Gonçalves; FLECK, Carolina Freddo; VIANA, João Garibaldi Almeida. Discriminação do Gênero Feminino no Ambiente de Trabalho: Um estudo de caso à luz da Teoria Institucional de Thorstein Veblen. In: ENCONTRO DA ASSOCIAÇÃO DOS PROGRAMAS DE PÓS-GRADUAÇÃO EM ADMINISTRAÇÃO, 43., 2019, São Paulo. Anais... São Paulo: ANPAD, 2019.

MOTTA. Fernando C. P. Masculino e feminino nas organizações: Relatório de Pesquisa 2. São Paulo: EAESP/FGV/NPP, 2000. Disponível em: < https://bibliotecadigital.fgv. $\quad$ br/dspace/bitstream/handle/10438/3070/Rel022000.pdf? sequence=1\&isAllowed=y>. Acesso em: 08 out. 2019.

MUNIZ, Danilo Dias; BACHA, Felipe Barcellos; PINTO, Júlia Massini. Participação Feminina no Mercado de Trabalho. Rev. Científica Eletrônica UNISEB, Ribeirão Preto, v.6, n.6, p.82-97, jul./dez.2015.

NARVAZ, Martha Giudice; KOLLER, Silvia Helena; Metodologias Feministas e estudos de Gênero: Articulando Pesquisa, Clínica e política. Psicologia em Estudo, Maringá, v. 11, n. 3, p. 647-654, set./dez., 2006. Disponível em: $<$ http://www.scielo.br/scielo.phpscript $=\quad$ sci_abstract\&pid=S1413$73722006000300021 \&$ Ing=en\&nrm=iso\&tlng=pt>. Acesso em: 24 ago. 2019

NISHIMURA, Maicon; ALPERSTEDT, Graziela Dias; FEUERSHÜTTE, Simone Ghisi. Empreendedorismo Social Feminino: Uma Pesquisa a Partir da História de Vida de Mulheres Empreendedoras. In: ENCONTRO DA ASSOCIAÇÃO NACIONAL DOS PROGRAMAS DE PÓS-GRADUAÇÃO EM ADMINISTRAÇÃO, 36., 2012, Rio de Janeiro. Anais... Rio de Janeiro: ANPAD, 2012.

NKOMO, Stella M.; COX JR, Taylor. Diversidade e Identidade nas Organizações. In: CLEGG, Stewart R.; HARDY, Cynthia; NORD, Walter R. (Orgs.). Handbook de Estudos Organizacionais. São Paulo: Atlas, 2006. p. 332-358.

OLIVEIRA, Isaac Gezer Silva de. Participação feminina nos Conselhos e Diretorias de Grandes Corporações. Apenas uma questão de gênero? In: ENCONTRO DE GESTÃO DE PESSOAS E RELAÇÕES DE TRABALHO, 5., 2017, Curitiba. Anais... Curitiba: ANPAD, 2017.

PINTO, Rosilaine Aparecida; MELO, Marlene Catarina de Oliveira Lopes. Delegadas na Policia Civil: Repercussões da Violência Simbólica no processo de Empoderamento. In: ENCONTRO DE ESTUDOS ORGANIZACIONAIS, 9., 2016, Belo Horizonte. Anais... Belo Horizonte: ANPAD, 2016a.

PINTO, Rosilaine Aparecida; MELO, Marlene Catarina de Oliveira Lopes. O que Eles pensam Delas? O Empoderamento de Delegadas da Polícia Civil na Perspectiva dos Delegados. In: ENCONTRO DA ASSOCIAÇÃO NACIONAL DOS PROGRAMAS DE PÓS GRADUAÇÃO EM ADMINISTRAÇÃO, 40., 2016, Costa do Sauipe. Anais... Costa do Sauipe: ANPAD, 2016b.

QUEVEDO-SILVA, Filipe et al. Estudo bibliométrico: orientações sobre sua aplicação. Brazilian Journal of Marketing, São Paulo, v. 15, n. 2, p. 246-262, abr./jun. 


\section{INSERÇÃO DE MULHERES NO MERCADO DE TRABALHO: UM ESTUDO \\ BIBLIOMÉTRICO DA PRODUÇÃO CIENTÍFICA NO PERÍODO DE 2009-2019}

2016. Disponível em: <https://www.redalyc.org/pdf/4717/471755312008.pdf>. Acesso em: 13 nov. 2020.

ROCHA, Rudimar Antunes; CERETTA, Paulo Sérgio. A pesquisa qualitativa: um desafio à ciência social. In: ENCONTRO DA ASSOCIAÇÃO NACIONAL DOS PROGRAMAS DE PRÓ-GRADUAÇÃO EM ADMINISTRAÇÃO, 22., 1998, Foz do Iguaçu. Anais... Foz do Iguaçu, ANPAD,1998, p. 1-14.

SANTOS, Jean Carlo Silva dos; ANTUNES, Elaine Di Diego. Relações de gêneros e liderança nas organizações: rumo a um estilo andrógino de gestão. Revista de Gestão Contemporânea, Porto Alegre, v. 10, n. 14, p. 35-60, 2013. Disponível em: http://seer2.fapa. com.br/index.php/arquivo. Acesso em: 09 set. 2018

SCHACTAE, Andréa Mazurok. A ordem e a margem: comportamento disciplinar para Polícia Feminina no Paraná (1977-2000). Tempo, Niterói-RJ, v. 21, n. 37, p.1-21, jun. 2015.

SCOTT, Joan Wallach. Gênero: uma categoria útil de análise histórica. Educação \& Realidade, Porto Alegre, v. 20, n. 2, jul./dez. 1995, p. 71-99.

SENKEVICS, Adriano Souza; CARVALHO, Marília Pinto de. O que você quer ser quando crescer? Escolarização e gênero entre crianças de camadas populares urbanas. Rev. Bras. Estud. Pedagog. Brasília, v. 97, n. 245, p. 179-194, abr. 2016.

SILVEIRA, Rachel. Os salários: Mantidas as condições desiguais? In: MARUANI, Margaret; HIRATA, Helena (Orgs.) As novas fronteiras da desigualdade: Homens e mulheres no mercado de trabalho. São Paulo: Editora Senac, 2003.

STEIL, Andréa V. Organizações, Gênero e Posições Hierárquicas compreendendo o fenômeno do teto de vidro. Revista de Administração de Empresas, São Paulo, v. 32, n. 3, p. $62-69,1997$.

TEIXEIRA, Rivanda Meira; BOMFIM, Lea Cristina Silva. Empreendedorismo feminino e os desafios enfrentados pelas empreendedoras para conciliar os conflitos trabalho e família: estudo de casos múltiplos em agências de viagens. Rev. Bras. Pesq. Tur., São Paulo, v. 10, n. 1, p. 44-64. Abr. 2016.

TOSTA, Tania Ludmila Dias. A participação de estudantes universitários no trabalho produtivo e reprodutivo. Cadernos de Pesquisa, São Paulo, v. 47, n. 165, p. 896-910 jul./set. 2017. Disponível em: <http://www.scielo.br/scielo.php?pid=S010015742017000300006\& ampscript=sci_abstract\&gt $>$. Acesso em: 06 nov. 2017.

VALE, Gláucia Maria Vasconcellos; SERAFIM, Ana Carolina Ferreira; TEODÓSIO, Armindo dos Santos de Sousa. Gênero, Imersão e Empreendedorismo: Sexo Frágil, Laços Fortes?. RAC, Curitiba, v. 15, n.4, p. 631-649, jul./ago. 2011. Disponível em: <http://www.scielo.br/pdf/rac/v15n4/a05v15n4.pdf\&gt>. Acesso em: 04 nov. 2017.

VAZ, Daniela V. O teto de vidro nas organizações públicas: evidências para o Brasil. Economia e Sociedade, Campinas, v. 22, n. 3, p. 765-790, dez. 2013. Disponível em: < http://www.scielo.br/pdf/ecos/v22n3/07.pdf>. Acesso em 10 out. 2019. 